\title{
On Marxist Ecological Thought and Its Practical Value
}

\section{Zhang Bei}

${ }^{1}$ College of Marxism, Guilin University of Electronic Science and technology, Guilin, Guangxi, China

E-mail: 392268756@qq.com

\begin{abstract}
The ecological problem is the fundamental problem of national construction and comprehensive, coordinated and sustainable development of society in the new era, which is related to the well-being of the people and the future of the nation. Under the new historical conditions, drawing lessons from and analyzing the ecological thoughts of Marx and Engels, and using the methods of dialectical materialism and historical materialism to analyze the self-consistency of "man and nature" and "man and society", which is of great practical significance for China to realize the balance between social equity and ecological harmony and to construct a new ecological civilization concept with Chinese characteristics.
\end{abstract}

Keywords: Marxism, ecological thought, ecological civilization construction, realistic value

\section{论马克思主义生态思想及其现实价值}

\section{张蓓}

${ }^{1}$ 桂林电子科技大学马克思主义学院, 桂林, 广西, 中国

392268756@qq.com

\section{摘要}

生态问题是新时期国家建构和社会全面协调可持续发展的根本问题，关乎人民的福祉和民族的未来。 树立科学的生态观，“努力走向社会主义生态文明新时代” ， [1] 既是马克思主义生态思想的生命根 基和本质要求，又是中国共产党一贯坚持的政治主张和执政理念。在新的历史条件下，借鉴和剖析马 克思、恩格斯的生态思想，运用辩证唯物主义与历史唯物主义的方法分析 “人与自然”、“人与社会” 的自洽性，这对于我国实现社会公平与生态和谐的均衡，构建中国特色的新型生态文明观具有重要的 现实意义。

关键词：马克思主义，生态思想，生态文明建设，现实价值

\section{1. 前言}

生态问题是新时期国家建构和社会全面协调可持 续发展的根本问题，关乎人民的福祉和民族的未来。树 立科学的生态观，“努力走向社会主义生态文明新时代”, 既是马克思主义生态思想的生命根基和本质要求, 又是 中国共产党一贯坚持的政治主张和执政理念。对此, 我 们应该站在世界观和方法论统一的高度, 积极探析借鉴 和剖析马克思、恩格斯的生态思想, 这是从理论上认识 和解决当代中国社会生态问题的重要议题。

\section{2. 马克思主义生态思想的主要内容}

马克思与恩格斯并没有对生态问题作专门的研究, 他们从历史唯物主义的视角对 “人与自然”、“人与社
会”、“人与人” 的自洽性分析, 却给人们呈现出了丰 富的生态思想, 给我们今天汲取马克思与恩格斯的生态 思想资源奠定了理论基础。具体而言，主要体现在以下 几个方面:

\section{1. 自然是客观存在的}

马克思认为, 自然是客观存在的, 是不以人的意志 为转移的, 而人本身就是自然界的产物, 人自身的一切 都是具有自然属性的, 是自然界的一部分, 所以人要与 自然保持一个和谐统一的状态。同时他也认为人的生存 发展是离不开自然的, 自然不仅提供了物质资料, 还为 人类提供了丰富的精神财富, 所以, 人一旦离开了自然, 就会失去所有的生产、生活资料。由此，我们就可以得 出, 自然是先于人和人的意识而存在的, 人类是自然的 一部分并且以来自然而存在，破坏自然就是毁灭人类自 身。 


\section{2. 人与自然是辩证统一的}

在人与自然的关系上，人是主体，自然是客体，而 这二者是通过实践来实现统一的。马克思和恩格斯认 为, “任何人类从自然界的长期发展中产生的, 形成了 人与自然环境之间的相互联系, 并且强调人与自然的统 一性，即人与自然关系的协调。”[2]在原始社会中， 人的生活、生产资料都直接的来源于自然, 人必须紧紧 依赖于自然才能活下去, 人们对自然是一种崇拜、敬畏 的心理，但随着生产力的发展，人类开始追求更多的生 活、生产资料, 开始大肆的改造自然、征服自然, 不断 向自然索取, 而在这改造、征服、索取的过程中, 人与 自然的关系发生了根本上的转变, 由开始的被动到了主 动, 自然变成了人类的对象。马克思和恩格斯认为, “社 会劳动实践搭建起了人与自然之间的主客体关系的桥 梁。” [3]人类通过劳动, 不断将一个原始的自然, 改 造成一个 “人化自然” , 不断地向自然索取。“人类 通过劳动不断的实现自然的 “人化” ，自然界的变化发 展和人类活动的辩证性在实践活动中体现出来。” 由此 可以看出, 在人与自然的关系中, 人是主体, 作用于自 然, 而这二者又是通过实践活动来达到一个和谐发展的 状态。但在实践活动中, 人类仍然要尊重自然, 正确地 认识和利用自然规律, 而不是盲目地创造和消灭它, 只 有这样做, 才能保持人与自然的和谐统一, 才能达到我 们所预期的结果, 实现可持续发展。

\section{3. 社会制度会导致生态危机的出现}

导致生态危机出现的真正原因是社会制度的不完 善。“资本主义生产使它汇集在各大中心的城市人口越 来越占优势, 这样一来, 它一方面社会聚集的历史动力, 另一方面有破坏着人类和土地之间的物质交换, 也就是 使得人以衣食形式消费掉的土地组成部分不能回到土 地，从而破坏土地持久肥力的永恒的自然条件” [4]资 本主义的生产方式破坏了人与自然原本的生存状态, 破 坏了生态环境, 同时还损害了人类自身的生存条件。所 以, 生态危机出现的根本原因就是资本主义生产方式的 占有同自然之间的矛盾关系, 是资本家为获取最大利益 与占有自然资源之间的矛盾关系。在马克思看来, 资本 主义制度是导致生态危机的根本原因, 所以就必须改革 不合理的社会制度。马克思与恩格斯认为, 资本主义使 人与自然的关系以一种异化的形式表现出来, 而要想重 新规范人与自然的关系, 就必须要改变资本主义的生产 方式和社会制度, 通过调节社会制度来调节人与自然的 关系。在马克思看来, 只有在共产主义社会中, 自然界 在人看来才是联系人与人的桥梁和纽带, 人们才能摆脱 资本主义私有制的剥削和异化劳动, 合理地调节人与 人、人与自然的关系。所以, 马克思认为要想解决生态 环境问题就必须要改革不合理的社会制度, 实现共产主 义, 从根本上解决人与自然的矛盾, 进而达到人与自然 的和谐统一。

\section{3. 中国生态文明建设中存在的问题}

\section{1. 生态环境制度不完善}

生态环境保护制度不完善, 主要的问题就是在立法 体系方面有待完善, 并且环境执法也不完备。具体就体 现在以下几点: 首先, 还没有征收专门的环境税。虽然 在税收中也有许多与环境相关的税种, 涉及到了机动车 辆、自然资源、废弃物管理和污染排放等领域, 但是由 于这些税种并非专门针对环境保护的，所以各税种之间 缺乏联系与协调, 没有充分的发挥到保护环境的作用。 其次, 在环境保护的价格上, 并没有形成完整的价格体 系。排污的成本低于废弃物处理成本, 这就导致一些企 业不完善资源再生相关制度, 也不会真正解决污染物的 治理。最后, 就是环境执法不完备。由于受到行政管理 体制与法律制度的不完善的影响, 执法主体出现混乱, 执法力度不够, 对现实的约束力不强, 并且执法手段也 比较单一, 多为罚款, 这就导致环境保护制度的执行不 能落到实处, 也没有真正的起到环境保护的作用。

\section{2. 环境的监管法制制度不完善}

首先, 排污的收费较低, 对其的惩罚力度不够, 环 境经济学在这一方面坚持的原理是 “排污费标准应当高 于治理成本”, 而中国恰好相反, 治理的成本是远远的 高于排污的收费, 同时对于严重的超标排污行为的处罚 力度太轻, 仅仅是采取罚款的形式, 并且罚款金额较少, 这就导致了许多企业宁愿掏排污费，也不愿投资建设相 关的废物处理设施。其次，环境法规规定的行政处罚方 式单一, 主要以罚款的方式为主, 并且金额少, “如对 超标排污行为规定罚款最高限额 10 万元, 对违反环评 擅自开工建设行为规定罚款最高限额 20 万元, 对水污 染严重超标的违法行为最高罚款限额为 100 万元。” 但 是对于企业来说, 获得生产时间和最终的生产利润才是 最重要的, 这一点处罚对他们来说, 只要是不影响生产, 都是微不足道的, 但是, 他们对于自然与社会带来的危 害远远超出他们所缴纳的罚款。最后, 环境的执法力度 不够, 许多地方为了促进当地的经济发展, 往往忽视对 环境的破坏, 使得环境保护的法律都是流于形式, 并没 有真正做到有法必依、违法必究、执法必严, 使得环境 监管不能落到实处。

\section{3. 社会公众的参与度不高}

生态文明建设是一个需要全社会共同参与的活动, 不能仅仅依靠政府及一些政策的制定实施，而我国现在 在生态文明建设这一过程中面临的最大的难题就是公 众的参与度不高, 不能调动起公众的积极性。而这种参 与度的不高就主要体现在一些环保组织只是流于形式, 并没有发挥到真正的作用，许多地区没有专业的人来指 
导。首先从环保组织这一方面看, 现在有许多各式各样 的环保组织, 但这些环保组织平时都是闲散的, 只有在 某些特定的时间才会组织一些环保宣传、环保活动等, 并没有真正达到环保的目的。其次就是许多地方上缺乏 专业的环保工作者, 许多地方在发展过程中一味的追求 经济的快速发展, 对环境的考虑缺乏, 若有专家提供一 些专业的自导, 则会产生更加理想的效果。最后一点就 是公民自身的参与度不高、积极性不强, 许多环保活动 都是在政府的组织下进行的，公民并没有自主性与主动 性, 就如每年的植树节, 只有一些单位、学校组织植树 活动, 并且许多人都是不情不愿的参加, 都抱着能逃就 逃、能躲就躲的心态, 并没有人民主动提出去参加, 参 与的热情并不高。由此, 我们就可以看出, 我国在生态 建设过程中, 还需要不断提高公民的参与度, 完善相关 的制度，真正达到环保的目的。

\section{4. 马克思主义生态思想对我国生态文明建 设的启示}

根据马克思主义生态思想的内容, 在生态文明建设 中, 要先保障生态文明建设的成果, 首先关键在于改革 不合理的社会制度, 建设能够促进生态文明进程的生态 制度体系, 形成一个经济发展与生态环保协调发展的关 系, 真正做到可持续发展。

\section{1. 建立完善的环境保护制度}

要是实现经济的可持续发展, 就必须要做到节能减 排, 这也就需要各个地区、各个主体之间因地制宜, 根 据自身的资源状况、产业结构及经济结构来合理的安排 节能减排的指标, 而要想完成这些就必须要有一套完善 的制度来保障。具体的还表现在没有征收专门的环境 税, 这就导致许多机构不能做到责任到人, 所以要建立 专门的绿色税收体系, 对一些重污染的地区及企业实行 征税, 让经济与环保直接挂钩, 加强人们对环保的认识。 其次, 在环境保护的价格方面, 要适当提高价格, 提高 排污的费用, 对一些重度污染的企业要加大处罚力度。 最后, 就是建立一套详细的执法体系, 加强执法的力度, 做到责任到人，并且丰富执法手段。

\section{2. 加强环境监管法制制度建设}

首先, 提高环境违法的成本, 建设完备的处罚机制, 由于现在排污收费低, 处罚不严, 导致许多企业宁可交 罚款也不去治理, 所以应该建立完备的处罚机制, 对于 违法排污的行为进行严厉的处罚, 并交纳数倍的排污 费, 同时对环境破坏严重者, 则应追究相应的法律责任, 总之, 就是要加大处罚力度, 丰富执法形式, 也可以令 其停产或是停工, 让其感到紧迫感与危机意识, 令其建 立相应的排污设备, 把经济利益与环境的保护紧密联
系。最后, 就是要加强环境执法力度, 环境执法部门并 没有延伸到乡镇基层, 所以乡镇在发展本地经济时, 仍 然我行我素，对环境的污染破坏置之不理，所以就要在 乡镇基层设立专门的环保部门, 并由以上一级直接管 理; 同时, 要加大对环境执法建设的投入, 提高执法水 平，不断提高执法队伍人员的专业水平与能力，使他们 真正意义上了解到环保的重要性, 并真正参与到环保建 设中来。

\section{3. 提高社会公众的参与度}

提高社会公众的参与度，推进全体公民的积极参 与。这就具体体现在以下几个方面: 首先, 在各地区设 立专门的环保部门, 并培养专业的人才, 为该地区在发 展经济和环境保护方面提供专业的意见与指导，协调经 济的可持续发展。其次, 设立一个专门的机构来直接领 导各种各样的环保组织, 在思想上提高这些环保组织的 认识, 并在经费等方面给予一定的支持, 加强环保宣传, 增加环保活动, 真正的发挥到他们的作用。再次, 提高 公民的环保意识，党的十八大报告指出：“加强生态 文明宣传教育, 增强全民节约意识、环保意识、生态意 识，形成合理消费的社会风尚，营造爱护生态环境的良 好风气” [5] 通过宣传教育, 来增加公民对环境保护的 认识以及认识到当前环境问题的严重性, 使更多的人认 识到我们自身的发展是与环境密切联系的, 增加他们参 加环保活动的积极性, 提高他们的参与热情。最后, 就 是要全力倡导绿色消费, 政府要大力扶植发展绿色产 业, 强化对非绿色产品的生产限制, 建立权威的绿色标 识制度，同时要构建促进绿色消费的税收管理体制，引 领消费者购买绿色环保且耐用的产品, 最终达到生态文 明建设的目的。

生态问题是一个社会问题，只有真正解决了这些社 会问题, 生态危机才能解决, 进而达到一个人与自然和 谐相处的状态。马克思主义生态思想就为当前我国生态 文明建设提供了理论的指导, 为我国生态问题的解决指 明了方向。

\section{REFERENCES}

[1] Xi Jinping. (2014) talk about governing the country. Beijing.

[2] Zhu Xianchen. (2011) Marxist ecological thought and its practical guiding value. seeking truth from facts.,7.

[3] Wang Ying. (2010) Enlightenment of Marxist Ecological Thought on Transformation of economic development mode. scientific socialism.,133.

[4] Marx. (2004) Das Kapital, Vol. 1. Beijing. People's publishing house.,597.

[5] Guidance book for the report of the 18th CPC National Congress,. (2012) Beijing. 